\title{
Do the positioning variables of the cage contribute to adjacent facet joint degeneration? Radiological and clinical analysis following intervertebral fusion
}

\author{
Fuping $\mathrm{Li}^{1,2,3 \#}$, Xinhua Zhan ${ }^{4,5 \#}$, Xin $\mathrm{Xi}^{1,2}$, Zhili Zeng ${ }^{1,2}$, Bin $\mathrm{Ma}^{1,2}$, Ning Xie ${ }^{1,2}$, Rui Zhu ${ }^{2}$, \\ Tsung-Yuan Tsai ${ }^{6}$, Guoan $\mathrm{Li}^{7}$, Yan $\mathrm{Yu}^{1,2}$, Liming Cheng ${ }^{1,2}$ \\ ${ }^{1}$ Department of Spine Surgery, Tongji Hospital, Tongji University School of Medicine, Shanghai, China; ${ }^{2}$ Key Laboratory of Spine and Spinal Cord \\ Injury Repair and Regeneration, Ministry of Education, Tongji Hospital, Tongji University School of Medicine, Shanghai, China; ${ }^{3}$ Department of \\ Spine Surgery, Shanghai Fourth People's Hospital Affiliated to Tongji University School of Medicine, Shanghai, China; Jiading Branch of Shanghai \\ General Hospital, Shanghai, China; ${ }^{5}$ Department of Orthopedics, Jiangqiao Hospital, Shanghai, China; ${ }^{6}$ School of Biomedical Engineering, Shanghai \\ Jiao Tong University, Shanghai, China; ${ }^{7}$ Orthopedic Bioengineering Research Center, Department of Orthopedic Surgery, Newton-Wellesley, \\ Hospital/Harvard Medical School, Wellesley, MA, USA \\ Contributions: (I) Conception and design: R Zhu, TY Tsai, L Cheng, G Li, Y Yu; (II) Administrative support: L Cheng, Y Yu, Z Zeng, B Ma, N Xie; \\ (III) Provision of study materials or patients: L Cheng, Y Yu, Z Zeng, B Ma, N Xie; (IV) Collection and assembly of data: F Li, X Zhan, X Xi; \\ (V) Data analysis and interpretation: F Li, X Zhan, Y Yu, G Li; (VI) Manuscript writing: All authors; (VII) Final approval of manuscript: All authors. \\ \#These authors contributed equally to this work. \\ Correspondence to: Yan Yu. Department of Spine Surgery, Tongji Hospital, Tongji University School of Medicine, Shanghai 200065, China. \\ Email: yuyan_83@hotmail.com.
}

Background: Compared to other risk factors, adjacent facet joint degeneration (AFD) is the main contributor to adjacent segment disease (ASD). The interbody cage may be a potential indirect risk of AFD. This study investigated the correlations among the lumbar sagittal balance parameters, the inter-body cage's intraoperative positioning variables, and adjacent facet joint degeneration following the transforaminal lumbar interbody fusion (TLIF) technique.

Methods: Patients who accepted single-level TLIF for symptomatic lumbar degenerative disease and were followed up for at least six months were enrolled in this study. According to the inclusive and exclusive criteria, 93 patients were included (44 males and 49 females). X-ray and computed tomography (CT) images were obtained before and six months after surgery. The vertebral contour and the center of the marker mass in the cage were calculated using a geometric algorithm. Orthopedic surgeons measured the disc height, lordosis angle, and facet joint degeneration. Patient-reported outcomes, including the Oswestry Disability Index (ODI) and the visual analog scale (VAS), were used to assess the clinical outcomes. The Student's t-test, Wilcoxon rank-sum test, and Chi-square test were used for the statistical analyses.

Results: The average age was 53.7 years old (range, 27-84 years). The average functional disability outcome assessed by the ODI was 61.2, and the average back and leg pain assessed by the VAS was 6.2 and 6.9, respectively. The patients were categorized into a normal group and an abnormal (AFD) group according to whether the facet joint degeneration was aggravated. The abnormal group had a higher back pain VAS score $(\mathrm{P}=0.031)$ and lower sagittal vertical position $(\mathrm{P}=0.027)$. The other parameters were similar at baseline $(\mathrm{P}>0.05)$. The cage's sagittal vertical position decreased significantly with AFD aggravation (OR, 0.737; 95\% CI, 0.561-0.969).

Conclusions: In patients with AFD aggravation, the preoperative VAS and postoperative ODI scores were significantly higher. The cage position parameters were related to AFD. A lower cage center was associated with a greater incidence of AFD.

Keywords: Adjacent segment disease (ASD); adjacent facet joint degeneration (AFD); interbody cage; transforaminal lumbar interbody fusion 
Submitted Nov 29, 2020. Accepted for publication Mar 05, 2021.

doi: $10.21037 /$ atm-20-7718

View this article at: http://dx.doi.org/10.21037/atm-20-7718

\section{Introduction}

Spinal fusion was first reported for the treatment of Pott's disease and spinal deformity. Decades later, adjacent segment disease (ASD) was reported as an unusual complication in patients who accepted intervertebral fusion (1). Recently, ASD is increasingly recognized as one of the most common complications after fusion surgery. Current studies suggest that spinal fusion surgery is more likely to result in ASD that compromises neurologic function at the adjacent segment. However, both the pathological and biomechanical mechanisms remain controversial (2). As an undesirable result, the phenomenon of segmental instability after fusion was found in $45 \%$ of patients (3), and the reoperation rate was as high as $31 \%$ (4). Therefore, enhanced knowledge of ASD avoidance, recognition, and management remains an essential objective for spinal surgeons.

Although the mechanism of ASD remains controversial, the reported potential risk factors for ASD include age, sex, segment, number of fusion segments, disc degeneration, facet joint degeneration, operation mode, menopause state, and sagittal alignment (5). Compared to other risk factors, adjacent facet joint degeneration (AFD) is generally considered more critical in ASD development (6). Theoretically, AFD is more likely to damage the facet joint and subsequently accelerate the adjacent segment degeneration as the pedicle screw violates the facet joint (7). Our previous study argued that the facet joint violation rate was as high as $39.39 \%$ after minimally invasive transforaminal lumbar interbody fusion (MIS-TLIF) (8); this finding implies a high potential risk of ASD caused by the socalled posterior implant.

As another key aspect of the anterior implant, the cage should be considered as a potential factor for complications. It has been reported that the cage is the main contributor to regional lordosis in sagittal alignments and is associated with clinical outcomes and AFD (9-11). Anterior positioning with sufficient space behind the cage is recommended to determine optimal lordosis (9) and prevent posterior cage migration (12). Biomechanically, the cage's strain has been previously analyzed in a cadaveric study, which concluded that a posterolateral placement on the stronger epiphysis contributed to cage subsidence prevention (13).

To the best of our knowledge, the clinical effect of intraoperative cage positioning has not been previously discussed in the context of AFD. We hypothesized that the incidence of AFD at short-term follow-up was almost 50\% in patients who underwent TLIF surgery. Furthermore, the cage positioning variables were significantly related to postoperative AFD and patient-related outcomes. Therefore, this study aimed to investigate the correlation between cage parameters and AFD. We present the following article following the MDAR checklist (available at http://dx.doi.org/10.21037/atm-20-7718).

\section{Methods}

\section{Study design and consent}

The study was conducted in accordance with the Declaration of Helsinki (as revised in 2013). The study was approved by ethics board of Tongji Hospital of Tongji University (No.: K-2017-008) and individual consent for this retrospective analysis was waived.

\section{Inclusion and exclusion criteria}

The inclusion criteria were as follows: (I) age >18 years; (II) accepted for single-level TLIF for symptomatic lumbar degenerative disease; (III) the X-ray film of the lumbar spine in the frontal and lateral view before and after surgery was available and could be recognized by the software; (IV) patients were followed up for more than six months, and $(\mathrm{V})$ the implanted cages were the same type and size. The exclusion criteria were as follows: (I) Lumbar surgery history; and (II) lumbar deformity, infection, tumor, or trauma.

\section{Follow-up method}

The patients were followed up for at least six months before and after the surgery. Both standard anteroposterior and lateral X-rays of lumbar and lumbar CT were taken. According to the inclusion and exclusion criteria, the preoperative and postoperative X-ray and CT image data of patients who underwent TLIF from January 2013 to June 2016 were obtained. The adjacent facet joint 


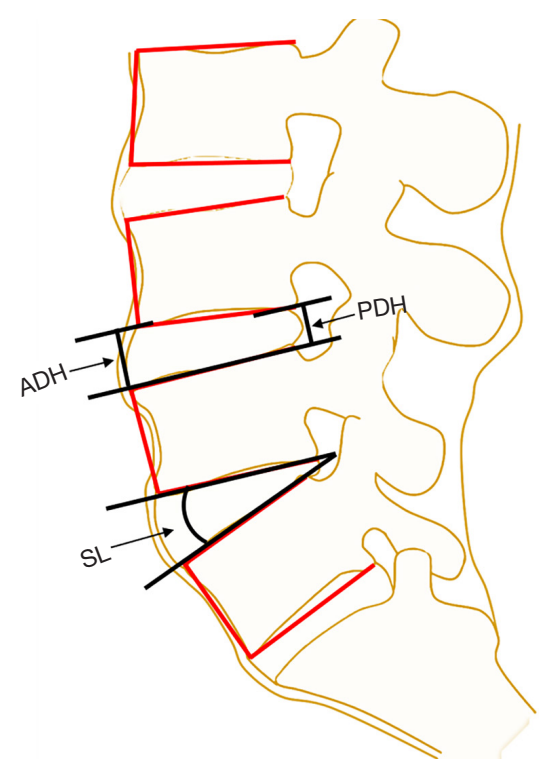

Figure 1 Recognition of vertebral margins via $\mathrm{X}$-ray films and calculation of AHD, PDH and SL parameters. degeneration grades were assessed via the lumbar CT image. The CONCORDE ${ }^{\circledR}$ Bullet lumbar interbody cage (Depuy Synthes, 325 Paramount Drive Raynham, MA), intervertebral space height, vertebral height, and lordosis angle were measured by spinal surgeons (Figure 1). Demographic characteristics, including age, gender, and body mass index (BMI), were collected for all patients at the beginning of this study. Patient-reported outcomes, including the ODI and VAS scores, were collected at follow-up. For the ODI, a higher score corresponds with better function, while for VAS, a higher score indicates worse symptoms.

\section{Measurement of lumbar parameters}

The anterior disc height, posterior disc height, lordosis angle in the fusion segment, and adjacent intervertebral space were measured, as well as lumbar lordosis. According to the Weishaupt classification (14) (Figure 2 \& Table 1),
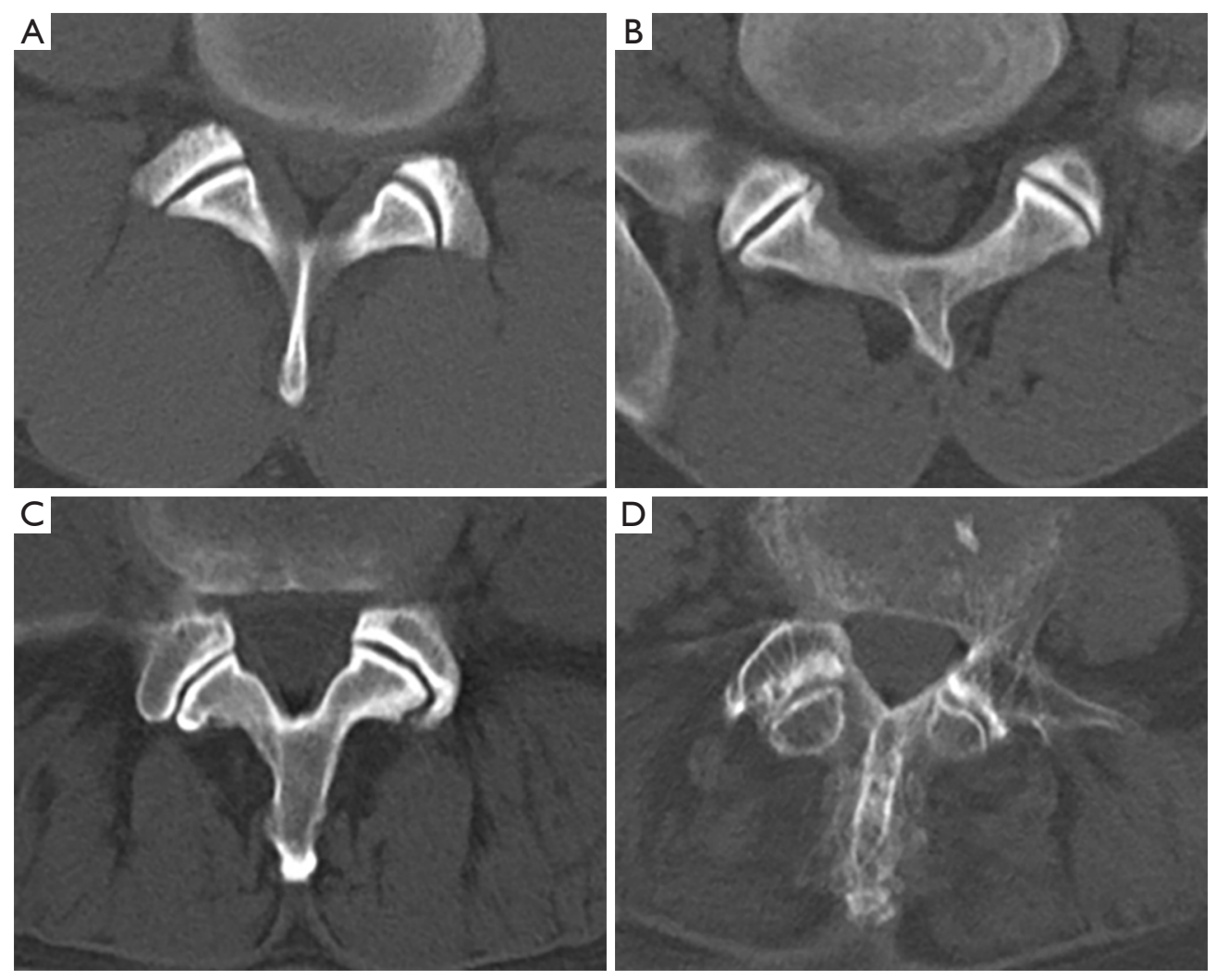

Figure 2 Facet joint degeneration grade illustrations. (A) Grade 0; (B) Grade 1; (C) Grade 2; (D) Grade 3. 
Table 1 Weishaupt classification

\begin{tabular}{ll}
\hline Grade & Criteria \\
\hline 0 & Normal facet joint space $(2-4 \mathrm{~mm}$ width) \\
1 & Narrowing of the facet joint space $(<2 \mathrm{~mm})$ and/or small osteophytes and/or mild hypertrophy of the articular process \\
2 & $\begin{array}{l}\text { Narrowing of the facet joint space and/or moderate osteophytes and/or moderate hypertrophy of the articular process and/ } \\
\text { or mild subarticular bone erosions }\end{array}$ \\
3 & $\begin{array}{l}\text { Narrowing of the facet joint space and/or large osteophytes and/or severe hypertrophy of the articular process and/or } \\
\text { severe subarticular bone erosions and/or subchondral cysts }\end{array}$
\end{tabular}

A

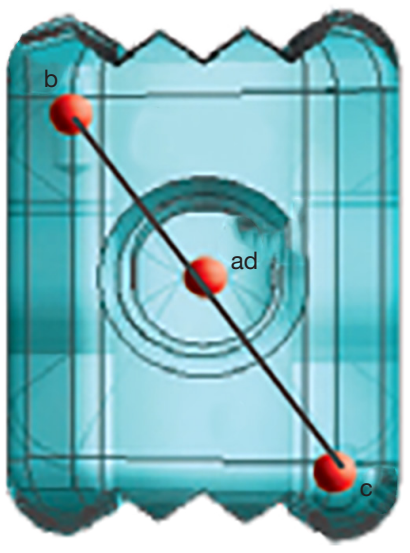

C

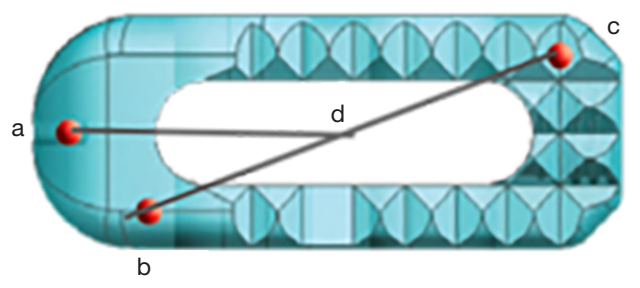

B

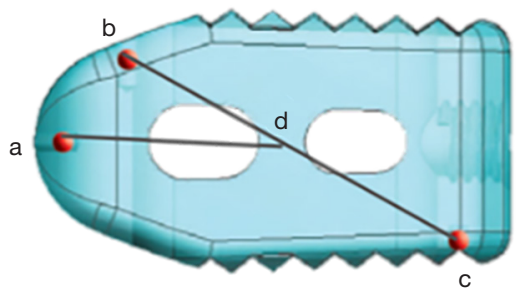

D

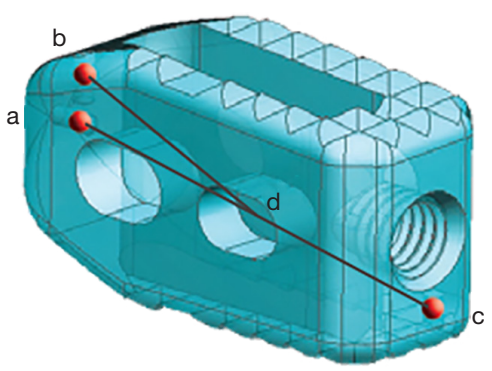

Figure 3 (A) Coronal plane view of the cage; (B) sagittal plane view of the cage; (C) axial plane view of the cage; (D) 3D view of CONCORDER Bullet lumbar interbody cage (Depuy Synthes).

two spinal surgeons' grade of degeneration of the facet joint was evaluated. If the evaluation results were inconsistent, another senior physician was required to provide an evaluation. The evaluation of the senior physician prevailed.

\section{Measurement of cage parameters}

As shown in Figure 3: Point $a$ is the tip of the cage; point $b$ is the position next to point $a$; point $c$ is the farthest position at the back of the cage; point $d$ is the intersection point of the line $b c$ (as the center point of the cage), and line $a d$ is the center axis of the cage. As shown in Figure 4A: Points $a, b$, and $c$ are the three feature recognition points of the cage. $C C$ is the center point of the cage, and the middle axis of the cage is the line between $a$ and CC. As shown in Figure 4B: $y 1 y 2$ represents the vertical centerline of the lumbar. The line through the lower endplate's anterior and posterior points in the fusion level was set as the horizontal position 

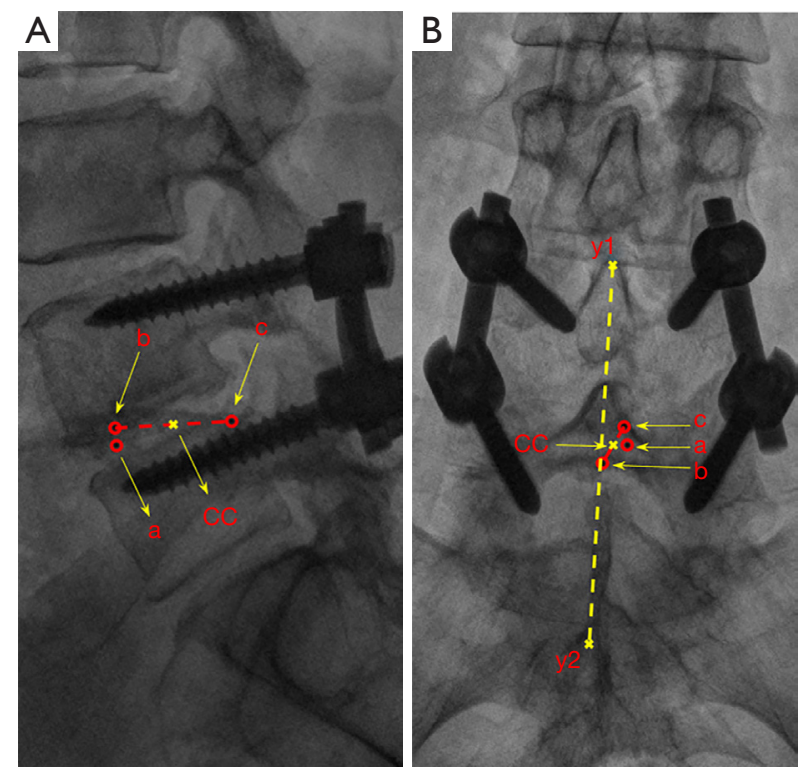

Figure 4 (A) Measurement of cage parameters in the sagittal plane; (B) measurement of cage parameters in the coronal plane.

to set up the coordinate system.

\section{Statistical analysis}

Patients were assigned to either a normal or abnormal (AFD) group dependent on whether the facet joint degeneration was aggravated, as assessed by two independent spinal surgeons. The patients' demographic and clinical characteristics, including age, gender, BMI, cage, disability, and pain measurements, were assessed by descriptive statistics. For continuous variables, comparisons between groups were assessed using the Student's t-test or Wilcoxon rank-sum test as appropriate. For categorical variables, comparisons between groups were assessed using the chi-square test. For the ODI measurement, a mixed-effect linear model with repeated measures analysis was used, in which the group, visit, and the interaction between group and visit were set as fixed effects. Individual patients were set as random effects. The same approach was used for the other longitudinal continuous outcomes, including the back and leg pain VAS scores. Variables significant at the 0.1 level in the univariate analyses were selected as candidates for a multivariate logistic regression model. Stepwise elimination model-building with a bootstrap approach (using 1,000 bootstrap samples of all the data) was used to select the independent variables to be retained in the final model. Before the final model construction, collinearity among the predictor variables was checked using the variance inflation factor (VIF). We considered collinearity to be present if the VIF of the variables was greater than 5 . All statistical analyses were performed using SAS version 9.4 (SAS Institute, 100 SAS Campus Drive Cary, NC 27513-2414, USA), and a two-sided $P$ value $<0.05$ was considered significant.

\section{Results}

\section{Study population characteristics and prevalence of joint degeneration}

A total of 93 patients (44 males and 49 females), including 69 cases of lumbar spinal stenosis and 24 cases of lumbar disc herniation, respectively, were included in the study. The average age of patients was 53.7 years (range, 27-84 years), the average functional disability outcome as assessed by the ODI was 61.2, and the average back and leg pain assessed by the VAS was 6.2 and 6.9, respectively. The most common surgical segment was L4/5 (53.8\%) and L5/S1 (37.6\%), and the prevalence of joint degeneration after surgery was $53.8 \%(50 / 93)$. The abnormal group had a higher back pain VAS score $(\mathrm{P}=0.031)$ and lower sagittal vertical position $(\mathrm{P}=0.027)$. However, the other parameters were similar at baseline (each $\mathrm{P}>0.05$ ). Table 2 summarizes the patients' demographic and clinical characteristics.

\section{Pain and functional disability outcome}

After the operation, both groups [mean, 14.2 (95\% CI, 12.9-15.5) for the normal group vs. 16.0 (95\% CI, $14.8-$ 17.2) for the AFD group] showed a significant improvement in their ODI scores (both $\mathrm{P}<0.001$ ). The between-group difference in the ODI score was -1.8 (95\% CI, -3.5 to $0 ; \mathrm{P}=0.049$ ). Both the normal group (mean, 3.4; $95 \% \mathrm{CI}$, 3.0-3.8) and the AFD group (mean, 3.8; 95\% CI, 3.4-4.1) reported significant improvement in the VAS for back pain $(\mathrm{P}<0.001$ for both groups) after surgery. This improvement continued six months after surgery [0.4 (95\% CI, 0.2-0.6) for the normal group and $0.7(0.5-1.0)$ for the AFD group]. Similar results were observed for the VAS leg pain scores (Table 3). In terms of pain assessment, there was no significant difference between the groups.

\section{Logistic regression analysis of related factors in an abnormal population}

Logistic regression analysis with stepwise elimination 
Table 2 Demographic and clinical characteristics of patients

\begin{tabular}{|c|c|c|c|c|}
\hline Characteristics $^{a}$ & Normal $(n=43)$ & Abnormal $(n=50)$ & Total $(n=93)$ & $P$ value \\
\hline Age (yr) & $52.6 \pm 14.3$ & $57.6 \pm 12.3$ & $53.7 \pm 13.4$ & 0.450 \\
\hline Male, n (\%) & $21(48.8)$ & $23(46.0)$ & $44(47.3)$ & 0.837 \\
\hline ODI & $60.6 \pm 3.0$ & $61.8 \pm 3.0$ & $61.2 \pm 3.1$ & 0.060 \\
\hline VAS for back pain & $5.9 \pm 1.1$ & $6.4 \pm 1.1$ & $6.2 \pm 1.2$ & 0.031 \\
\hline Segment, No. (\%) & & & & 0.200 \\
\hline L2/3 & 0 & $1(2.0)$ & $1(1.1)$ & \\
\hline L3/4 & $1(2.3)$ & $6(12.0)$ & $7(7.5)$ & \\
\hline $\mathrm{L} 4 / 5$ & $23(53.5)$ & $27(54.0)$ & $50(53.8)$ & \\
\hline Micro & $15(34.9)$ & $23(46.0)$ & $38(40.9)$ & \\
\hline Direction, n (\%) & & & & 0.090 \\
\hline Left & $22(51.2)$ & $16(32.0)$ & $38(40.9)$ & \\
\hline Right & $21(48.8)$ & $34(68.0)$ & $55(59.1)$ & \\
\hline \multicolumn{5}{|l|}{ Cage parameters } \\
\hline Angle between cage and endplate & $5.7 \pm 4.9$ & $4.0 \pm 6.5$ & $4.8 \pm 5.8$ & 0.157 \\
\hline Angle between cage and central line ${ }^{b}$ & $129.2(106.3-142.1)$ & $126.0(112.3-137.3)$ & $126.8(111.7-139.3)$ & 0.829 \\
\hline Coronal horizontal position & $2.4 \pm 4.4$ & $2.9 \pm 4.7$ & $2.7 \pm 4.5$ & 0.601 \\
\hline Angle between lower screw angle and endplate & $1.5 \pm 5.8$ & $3.3 \pm 5.6$ & $2.4 \pm 5.7$ & 0.144 \\
\hline \multicolumn{5}{|l|}{ Local balance parameters } \\
\hline Anterior height of upper intervertebral space & $1.7 \pm 0.3$ & $1.6 \pm 0.3$ & $1.7 \pm 0.3$ & 0.536 \\
\hline Posterior height of upper intervertebral space & $0.9 \pm 0.2$ & $0.9 \pm 0.3$ & $0.9 \pm 0.2$ & 0.998 \\
\hline Anterior height of surgery intervertebral space & $1.6 \pm 0.4$ & $1.6 \pm 0.4$ & $1.6 \pm 0.4$ & 0.894 \\
\hline Posterior height of surgery intervertebral space & $0.8 \pm 0.2$ & $0.9 \pm 0.4$ & $0.8 \pm 0.3$ & 0.091 \\
\hline Anterior height of lower intervertebral space & $1.7 \pm 0.4$ & $1.7 \pm 0.4$ & $1.7 \pm 0.4$ & 0.934 \\
\hline Posterior height of upper intervertebral space & $0.8 \pm 0.2$ & $0.8 \pm 0.2$ & $0.8 \pm 0.2$ & 0.299 \\
\hline Segmental lordosis of fusion level & $14.1 \pm 5.8$ & $12.8 \pm 6.9$ & $13.4 \pm 6.4$ & 0.326 \\
\hline Segmental lordosis of upper level & $9.5 \pm 6.1$ & $9.2 \pm 6.5$ & $9.3 \pm 6.3$ & 0.786 \\
\hline Segmental lordosis of lower level & $16.6 \pm 5.5$ & $14.9 \pm 5.8$ & $15.6 \pm 5.7$ & 0.246 \\
\hline Lumbar lordosis & $31.4 \pm 12.1$ & $32.4 \pm 13.9$ & $31.9 \pm 13.1$ & 0.704 \\
\hline
\end{tabular}

${ }^{\mathrm{a}}$ Data are expressed as mean with standard deviation unless otherwise indicated. ${ }^{\mathrm{b}}$ Presented as median with interquartile range. BMI, body mass index; ODI, Oswestry Disability Index; VAS, Visual Analog Scale. 
Table 3 Disability and pain assessment after operation

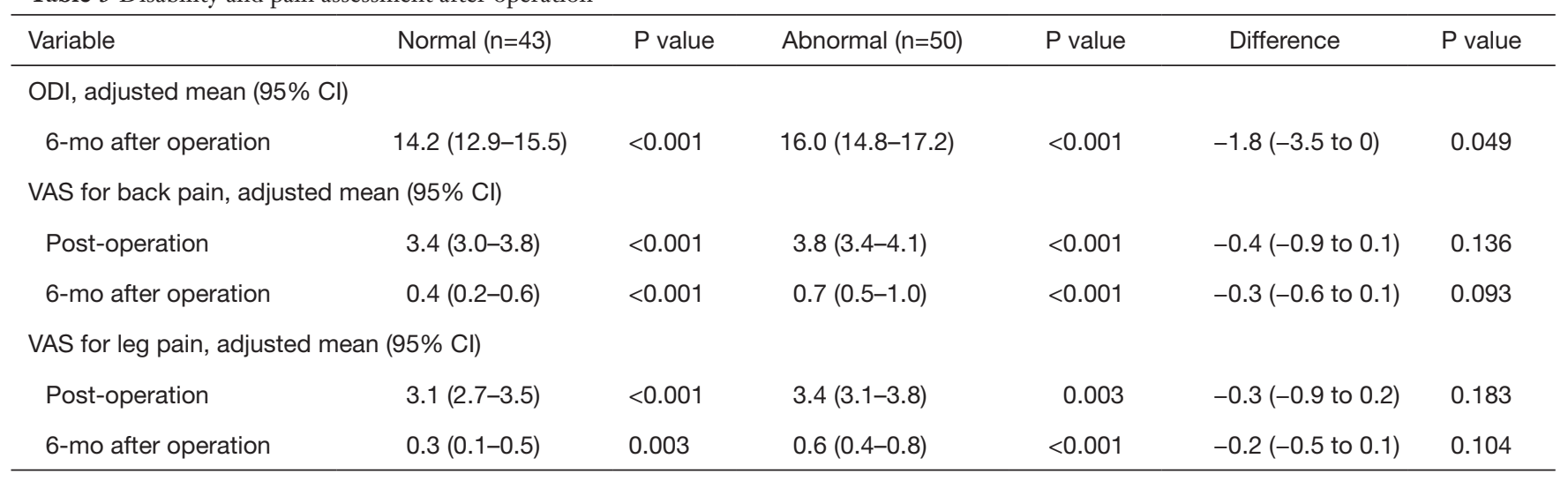

ODI, Oswestry Disability Index; VAS, Visual Analog Scale.

Table 4 Backward logistic regression with bootstrap method

\begin{tabular}{lcccc}
\hline Variables & B & SE & P value & Odds ratio (95\% CI) $^{\mathrm{a}}$ \\
\hline Intercept & -4.411 & 1.972 & 0.0253 & \\
Sagittal vertical position & -0.305 & 0.139 & 0.0287 & 0.737 (0.561 to 0.969) \\
Coronal endplate diameter of lower vertebrae & 0.127 & 0.055 & 0.0197 & $1.135(1.020$ to 1.263$)$ \\
\hline
\end{tabular}

${ }^{\mathrm{a}}$ Regression coefficient and corresponding odds ratio after bootstrapping.

identified five cage parameters and two diameters of the surgery level's lower endplate. No collinearities were observed among variables in the multivariate logistic regression analysis (VIFs < 1.5). After bootstrapping and adjustment for overfitting, the final model's ROC area was 0.704, with two independent variables: the cage's sagittal vertical position and the coronal endplate diameter lower vertebrae. Table 4 shows the regression coefficients and odds ratio per predictor adjusted for overfitting. The cage's sagittal vertical position decrease was significantly associated with AFD aggravation (OR, 0.737; 95\% CI, 0.561-0.969). Each unit of decreased sagittal vertical position of the cage increased the likelihood of joint degeneration by $35.7 \%$. Moreover, an increased coronal endplate diameter of the lower vertebrae was significantly associated with AFD (OR, 1.135 ; $95 \%$ CI, $1.020-1.263$ ) and signified that the odds of AFD increased $13.5 \%$ with each millimeter in the coronal endplate diameter of the lower vertebrae.

\section{Distribution of the cage center in the axial plane}

The horizontal parameters of the cage center point (\%, normalized to endplate size) were as follows: Normal group, front and back position, $-3.32 \pm 9.77$; left and right position, 5.66 \pm 11.57 ; abnormal group, front and back position, $-3.81 \pm 8.58$; left and right position, $7.86 \pm 11.63$. There was no significant difference between the groups in the frontback position $(\mathrm{P}>0.05)$ and the left-right position $(\mathrm{P}>0.05)$. The location probability of the cage center is shown in Figure 5.

\section{Discussion}

Previous studies suggest no correlation between postoperative clinical results (including VAS and ODI scores) and ASD after lumbar fusion surgery $(15,16)$. However, in the current study, the preoperative back pain VAS score $(\mathrm{P}=0.031)$ was higher in patients with AFD aggravation. A previous study suggested that AFD is one of the key factors in lower back pain (17). Long-term lower back pain causes disuse atrophy of the paraspinal muscles, leading to the aggravation of ASD (6), thus forming a vicious circle. Furthermore, patients with AFD aggravation were likely to report a higher ODI score, and consequently, a poorer life quality. Therefore, spinal surgeons should pay close attention to AFD and intervention treatment, especially in patients with lower 

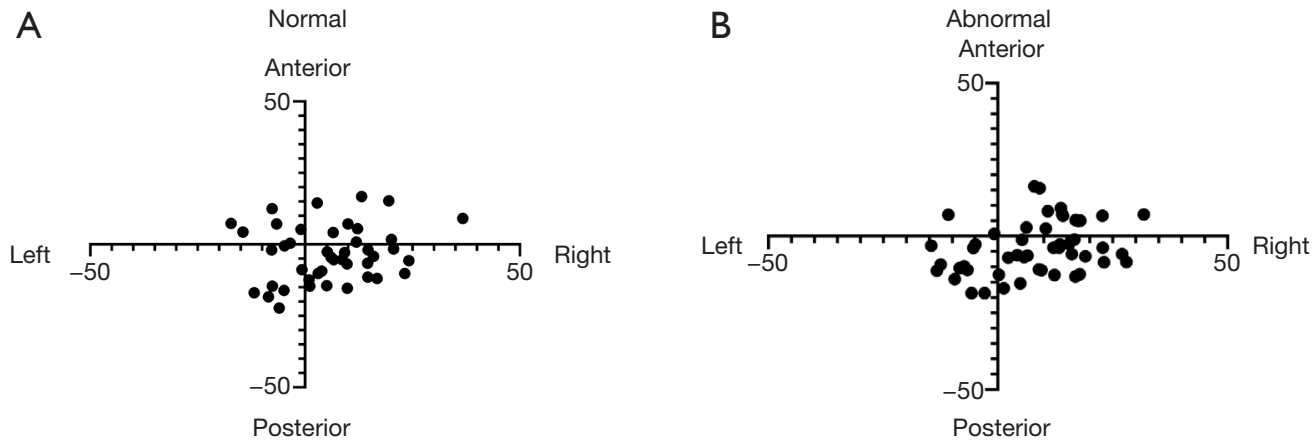

Figure 5 (A) Cages' horizontal position of the normal group; (B) Cages' horizontal position of the abnormal group.

back pain and poor postoperative ODI scores.

Most previous studies have focused on the relationship between cage parameters and the lumbar sagittal sequence, such as the intervertebral space height and the lordosis angle. Omidi-Kashani et al. suggest that after fusion surgery at the L4-L5 level, the intervertebral fusion cage may not significantly improve the radiological and clinical outcomes but may be related to more complications and morbidity (18). Furthermore,

Castellvi et al. found that the best cage position for acquiring stability is near the sagittal plane's midline (19). In our study, most of the cage positions were near the midline. Other studies pointed out that a large cage contributes to the recovery and maintenance of lumbar lordosis, segmental lordosis, and disc height (20-22).

Compared to disc degeneration, AFD plays a more critical role in developing ASD (6). Our results indicate a significant difference in the cage's vertical position between patients with and without progression in AFD $(\mathrm{P}<0.05)$. According to the logistic regression analysis, a lower cage center is associated with a greater probability of AFD (OR, 1.788; $\mathrm{P}=0.003)$.

The endplate contour is defined as the connection of the front and back edges of the endplate. Theoretically, the distance between the cage center and the two endplates should be equivalent. When the endplate was over-polished, the cage subsided to the lower endplate. Consequently, a lower cage position is presented in the $\mathrm{X}$-ray figure. Besides, overpolishing of the endplate caused endplate defects, resulting in inflammation, then transduction to the facet joint through the vertebral body, and finally aggravation of AFD (23).

The relative cage subsidence may decrease the disc height restoration and segmental lordosis $(24,25)$. Inadequate restoration of disc height and segmental lordosis plays an important role in ASD (especially disc degeneration) (26-29). Yang and Kim found that when the intervertebral space's height decreased, the normal facet joint would bear 3-25\% more vertical stress (30), which may accelerate AFD. Previous imaging studies have directly shown that a decrease in disc height accelerates AFD (31).

There were some limitations to the current study. The clinical sample size of 93 cases was modest. We did a power analysis with the following condition: using ODI for sample size calculation, the between-group difference was set as 1.8 points (14.2 in one group and 16.0 in the other), and a standard deviation of 3 points was set for the ODI difference. To achieve "power $=0.8$ ", a minimum of 90 clinical samples would be required. Our sample size was 93 and therefore met the minimum requirements. Many factors affect the accuracy of X-ray measurement data: In this study, to overcome the single plane error as much as possible, we carried out a unified shooting posture for all subjects. This study is a retrospective study without randomized control. The grade of AFD and age were not at the same level. These two factors were independent factors associated with AFD, but this is the first study to find cage space parameters related to AFD. However, further research and long-term follow-up with a greater number of patients is still needed.

\section{Conclusions}

In patients with AFD aggravation, the preoperative VAS and postoperative ODI scores were significantly higher. The cage space parameters were associated with AFD, insofar as the lower the cage center, the greater the probability of AFD. We suggest that the inferior endplate should be performed with care during surgery, especially for 
osteoporosis patients.

\section{Acknowledgments}

We want to thank AME editing (http://editing.amegroups. $\mathrm{cn} /$ \#editing) for English language editing.

Funding: This work was supported by the Shanghai Excellent Young Medical Talents Training Program (grant number 2018YQ22); the Shanghai Rising-Star Program (grant number 18QA1403800); and the National Natural Science Foundation of China (grant number 81873774).

\section{Footnote}

Reporting Checklist: The authors have completed the MDAR reporting checklist. Available at http://dx.doi.org/10.21037/ atm-20-7718

Data Sharing Statement: Available at http://dx.doi. org/10.21037/atm-20-7718

Conflicts of Interest: All authors have completed the ICMJE uniform disclosure form (available at http://dx.doi. org/10.21037/atm-20-7718). The authors have no conflicts of interest to declare.

Ethical Statement: The authors are accountable for all aspects of the work in ensuring that questions related to the accuracy or integrity of any part of the work are appropriately investigated and resolved. The study was conducted in accordance with the Declaration of Helsinki (as revised in 2013). The study was approved by ethics board of Tongji Hospital of Tongji University (No. K-2017-008) and individual consent for this retrospective analysis was waived.

Open Access Statement: This is an Open Access article distributed in accordance with the Creative Commons Attribution-NonCommercial-NoDerivs 4.0 International License (CC BY-NC-ND 4.0), which permits the noncommercial replication and distribution of the article with the strict proviso that no changes or edits are made and the original work is properly cited (including links to both the formal publication through the relevant DOI and the license). See: https://creativecommons.org/licenses/by-nc-nd/4.0/.

\section{References}

1. Lund T, Oxland TR. Adjacent level disk disease-- is it really a fusion disease? Orthop Clin North Am 2011;42:529-41, viii.

2. Radcliff KE, Kepler CK, Jakoi A, et al. Adjacent segment disease in the lumbar spine following different treatment interventions. Spine J 2013;13:1339-49.

3. Lehmann TR, Spratt KF, Tozzi JE, et al. Long-term follow-up of lower lumbar fusion patients. Spine (Phila Pa 1976) 1987;12:97-104.

4. Okuda S, Nagamoto Y, Matsumoto T, et al. Adjacent Segment Disease After Single Segment Posterior Lumbar Interbody Fusion for Degenerative Spondylolisthesis: Minimum 10 Years Follow-up. Spine (Phila Pa 1976) 2018;43:E1384-8.

5. Wang H, Ma L, Yang D, et al. Incidence and risk factors of adjacent segment disease following posterior decompression and instrumented fusion for degenerative lumbar disorders. Medicine (Baltimore) 2017;96:e6032.

6. Kim JY, Ryu DS, Paik HK, et al. Paraspinal muscle, facet joint, and disc problems: risk factors for adjacent segment degeneration after lumbar fusion. Spine J 2016;16:867-75.

7. Matsukawa K, Kato T, Yato Y, et al. Incidence and Risk Factors of Adjacent Cranial Facet Joint Violation Following Pedicle Screw Insertion Using Cortical Bone Trajectory Technique. Spine (Phila Pa 1976) 2016;41:E851-6.

8. Jia L, Yu Y, Khan K, et al. Superior Facet Joint Violations during Single Level Minimally Invasive Transforaminal Lumbar Interbody Fusion: A Preliminary Retrospective Clinical Study. Biomed Res Int 2018;2018:6152769.

9. Landham PR, Don AS, Robertson PA. Do position and size matter? An analysis of cage and placement variables for optimum lordosis in PLIF reconstruction. Eur Spine J 2017;26:2843-50.

10. Hu YH, Niu CC, Hsieh MK, et al. Cage positioning as a risk factor for posterior cage migration following transforaminal lumbar interbody fusion - an analysis of 953 cases. BMC Musculoskelet Disord 2019;20:260.

11. Park SJ, Lee CS, Chung SS, et al. The Ideal Cage Position for Achieving Both Indirect Neural Decompression and Segmental Angle Restoration in Lateral Lumbar Interbody Fusion (LLIF). Clin Spine Surg 2017;30:E784-90.

12. Park MK, Kim KT, Bang WS, et al. Risk factors for cage migration and cage retropulsion following transforaminal lumbar interbody fusion. Spine J 2019;19:437-47.

13. Briski DC, Goel VK, Waddell BS, et al. Does Spanning a Lateral Lumbar Interbody Cage Across the Vertebral Ring Apophysis Increase Loads Required for Failure and Mitigate Endplate Violation. Spine (Phila Pa 1976) 
2017;42:E1158-64.

14. Weishaupt D, Zanetti M, Boos N, et al. MR imaging and CT in osteoarthritis of the lumbar facet joints. Skeletal Radiol 1999;28:215-9.

15. Ha KY, Son JM, Im JH, et al. Risk factors for adjacent segment degeneration after surgical correction of degenerative lumbar scoliosis. Indian J Orthop 2013;47:346-51.

16. Chen BL, Wei FX, Ueyama K, et al. Adjacent segment degeneration after single-segment PLIF: the risk factor for degeneration and its impact on clinical outcomes. Eur Spine J 2011;20:1946-50.

17. Lewinnek GE, Warfield CA. Facet joint degeneration as a cause of low back pain. Clin Orthop Relat Res 1986;(213):216-22.

18. Omidi-Kashani F, Jalilian R, Golhasani-Keshtan F. Effect of interbody fusion cage on clinical and radiological outcome of surgery in L4-L5 lumbar degenerative spondylolisthesis. J Spine Surg 2018;4:109-14.

19. Castellvi AD, Thampi SK, Cook DJ, et al. Effect of TLIF Cage Placement on In Vivo Kinematics. Int J Spine Surg 2015;9:38.

20. Elmekaty M, ElMehy E, Forsth P, et al. Safety of a novel modular cage for transforaminal lumbar interbody fusion clinical cohort study in 20 patients with degenerative disc disease. SICOT J 2018;4:24.

21. Mica MC, Voronov LI, Carandang G, et al. Biomechanics of an Expandable Lumbar Interbody Fusion Cage Deployed Through Transforaminal Approach. Int J Spine Surg 2017;11:24.

22. Du L, Sun XJ, Zhou TJ, et al. The role of cage height on the flexibility and load sharing of lumbar spine after lumbar interbody fusion with unilateral and bilateral instrumentation: a biomechanical study. BMC Musculoskelet Disord 2017;18:474.

23. Jiang X, Chen D, Li Z, et al. Correlation between Lumbar

Cite this article as: Li F, Zhan X, Xi X, Zeng Z, Ma B, Xie N, Zhu R, Tsai TY, Li G, Yu Y, Cheng L. Do the positioning variables of the cage contribute to adjacent facet joint degeneration? Radiological and clinical analysis following intervertebral fusion. Ann Transl Med 2021;9(9):776. doi: 10.21037/atm-20-7718
Spine Facet Joint Orientation and Intervertebral Disk Degeneration: A Positional MRI Analysis. J Neurol Surg A Cent Eur Neurosurg 2019;80:255-61.

24. Uribe JS, Harris JE, Beckman JM, et al. Finite element analysis of lordosis restoration with anterior longitudinal ligament release and lateral hyperlordotic cage placement. Eur Spine J 2015;24 Suppl 3:420-6.

25. Uribe JS, Smith DA, Dakwar E, et al. Lordosis restoration after anterior longitudinal ligament release and placement of lateral hyperlordotic interbody cages during the minimally invasive lateral transpsoas approach: a radiographic study in cadavers. J Neurosurg Spine 2012;17:476-85.

26. Hashimoto K, Aizawa T, Kanno H, et al. Adjacent segment degeneration after fusion spinal surgery-a systematic review. Int Orthop 2019;43:987-93.

27. Bagheri SR, Alimohammadi E, Zamani Froushani A, et al. Adjacent segment disease after posterior lumbar instrumentation surgery for degenerative disease: Incidence and risk factors. J Orthop Surg (Hong Kong) 2019;27:2309499019842378.

28. Zhao X, Du L, Xie Y, et al. Effect of Lumbar Lordosis on the Adjacent Segment in Transforaminal Lumbar Interbody Fusion: A Finite Element Analysis. World Neurosurg 2018;114:e114-20.

29. Tian H, Wu A, Guo M, et al. Adequate Restoration of Disc Height and Segmental Lordosis by Lumbar Interbody Fusion Decreases Adjacent Segment Degeneration. World Neurosurg 2018;118:e856-64.

30. Yang KH, King AI. Mechanism of facet load transmission as a hypothesis for low-back pain. Spine (Phila Pa 1976) 1984;9:557-65.

31. Song Q, Liu X, Chen DJ, et al. Evaluation of MRI and CT parameters to analyze the correlation between disc and facet joint degeneration in the lumbar three-joint complex. Medicine (Baltimore) 2019;98:e17336. 